\title{
Concentrate and Solvent for Solution for Injection Dosage Form
}

National Cancer Institute

\section{Source}

National Cancer Institute. Concentrate and Solvent for Solution for Injection Dosage

Form. NCl Thesaurus. Code C149379.

Sterile concentrate and sterile solvent intended for the preparation of a solution for injection by diluting the concentrate with the solvent. 